\title{
Sonochemical Synthesis of Silver Nanoparticles Using Starch: A Comparison
}

\author{
Brajesh Kumar, ${ }^{1}$ Kumari Smita, ${ }^{1}$ Luis Cumbal, ${ }^{1}$ \\ Alexis Debut, ${ }^{1}$ and Ravinandan Nath Pathak ${ }^{2}$ \\ ${ }^{1}$ Centro de Nanociencia y Nanotecnologia, Universidad de las Fuerzas Armadas (ESPE), Sangolqui, Ecuador \\ ${ }^{2}$ Department of Chemistry, Kolhan University, Chaibasa, Jharkhand 833202, India
}

Correspondence should be addressed to Brajesh Kumar; krmbraj@gmail.com and Luis Cumbal; lhcumbal@espe.edu.ec

Received 21 October 2013; Revised 25 November 2013; Accepted 26 November 2013; Published 22 January 2014

Academic Editor: Konstantinos Tsipis

Copyright (C) 2014 Brajesh Kumar et al. This is an open access article distributed under the Creative Commons Attribution License, which permits unrestricted use, distribution, and reproduction in any medium, provided the original work is properly cited.

\begin{abstract}
A novel approach was applied to synthesize silver nanoparticles using starch under sonication. Colloidal silver nanoparticles solution exhibited an increase of absorption from 420 to $440 \mathrm{~nm}$ with increase starch quantity. Transmission electron microscopy followed by selected area electron diffraction pattern analysis indicated the formation of spherical, polydispersed, amorphous, silver nanoparticles of diameter ranging from 23 to $97 \mathrm{~nm}$ with mean particle size of $45.6 \mathrm{~nm}$. Selected area electron diffraction (SAED) confirmed partial crystalline and amorphous nature of silver nanoparticles. Silver nanoparticles synthesized in this manner can be used for synthesis of 2-aryl substituted benzimidazoles which have numerous biomedical applications. The optimized reaction conditions include $10 \mathrm{ml}$ of $1 \mathrm{mM} \mathrm{AgNO}_{3}, 25 \mathrm{mg}$ starch, $11 \mathrm{pH}$ range, and sonication for $20 \mathrm{~min}$ at room temperature.
\end{abstract}

\section{Introduction}

Nanoscale materials have received considerable attention because their unusual optical, chemical, photoelectrochemical, and electronic properties differ significantly from those of atoms and molecules as well as those of bulk materials [13]. The synthesis of nanomaterials with the desired quality is one of the most exciting aspects in modern nanoscience and nanotechnology [4]. Colloidal nanoparticles are small in diameter but large in surface area and huge in current many exclusive medical and industrial applications such as biological engineering, catalysts, and electronic devices [5]. Colloidal silver nanoparticle (Ag-NP) with natural macromolecule can be fabricated by physical $[6,7]$ and chemical reduction [8-10] methods. Nowadays, biomass starch as a raw material for the synthesis of Ag-Nps has reflected significant superiority in some process. However, no literature is available on its preparation in starch at different $\mathrm{pH}$ and polysaccharide by ultrasonic field. The sonochemical methods are as follows: formation, development, and the implosion of the microcavities [11]. When solutions are exposed to ultrasonic irradiation, bubbles in the solution could be imploded by acoustic fields. Cavitation's bubble collapse can also induce a shock wave in the solution and drive the rapid impact of the liquid to the surface of the particles [12]. Use of the sonoelectrochemical method for the preparation of spheres, rods, and dendrites shaped Ag-Nps with nitriloacetate (NTA) [13]. It was found that the electrolyte composition that comes along reaction time can greatly affect the shape and growth of the NPs. Branched silver structure with $\lambda_{\max } 440 \mathrm{~nm}$ and average diameter of $11.5 \mathrm{~nm}$ was formed using an aqueous extract of Mesua ferrea Linn. leaf [14]. Nagata and coworkers formed stable colloidal dispersions of silver prepared by ultrasonic irradiation of aqueous $\mathrm{AgNO}_{3}$ or $\mathrm{AgClO}_{4}$ solutions in the presence of surfactants [15]. Amorphous Ag-NPs of $20 \mathrm{~nm}$ size were prepared from an aqueous solution of $\mathrm{AgNO}_{3}$ using argon-hydrogen atmosphere [16] and $\mathrm{AgBr}$ in the presence of gelatin [17]. Sonochemical route using a hazardous reducing agent $\left(\mathrm{NaBH}_{4}\right)$ produced spherical silver nanoparticles of sizes $10 \mathrm{~nm}$ [18].

Many methods aiming at the formation of Ag-Nps, including the green ones, make use of an organic molecule. The latter interacts with the particles and provides them with stability against oxidation and agglomeration, or it can 
even act as a matrix only. In this sense, polymer molecules have been widely employed because their long chain offers many binding sites in which nanoparticles can be stabilized [19]. Moreover, natural polymers are extremely important because many of them are biocompatible and nontoxic. Among such biomolecules are sucrose [20], maltose [20], chitosan [21], Arabic gum [22], and plant extracts such as the ones obtained from Jatropha curcas [23], Murraya koenigii, [24] and Mangifera indica [25]. More specifically, the natural rubber latex (NRL) extracted from Hevea brasiliensis, a native tree from the Amazon forest, arises as a possible biomaterial for use in the synthesis of nanoparticles [26].

The use of green capping and stabilizing attribute of starch in aqueous solution has recently become important in synthesis methods of nanomaterials, due to the fact that this biopolymer acts as an effective surfactant agent and is environmentally friendly. It is possible to obtain Ag-NPs of spherical shape by using sago starch as coating agent [27]. Shervani et al. [28] synthesized silver NPs of 15 and $43 \mathrm{~nm}$ using $1 \mathrm{wt} \%$ aqueous solution of starch. Others studies [29, 30] found that stable Ag-NPs have could been synthesized by using soluble starch both as reducing and stabilizing agents, with sizes in the range of $10-34 \mathrm{~nm}$.

In this paper, we report a green approach toward the sonochemical synthesis and stabilization of Ag-Nps by using starch; and its application as a catalyst for synthesis 2-(2chlorophenyl)-1H-benzimidazole (Figure 1).

\section{Material and Methods}

2.1. Chemicals. All chemicals used were of analytical grade and used without any purification. Silver nitrate (99.0\%) was purchased from Spectrum (USA). Acetonitrile, ethyl acetate, hexane, substituted benzaldehyde, and $o$-phenylenediamine were purchased from Thomas Baker (INDIA). Millipore Milli-Q water was used in all experiments.

2.2. Synthesis and Characterization of Starched Ag-Nps. Preparation of starched Ag-Nps is quite straight forward. In a typical preparation, 25 and $30 \mathrm{mg}$ of starch was added to $10 \mathrm{~mL}$ of $1 \mathrm{mM}$ of $\mathrm{AgNO}_{3}$. The mixture was stirred for complete dissolution and agitated under sonication. Ultrasound irradiation was carried out with ultrasonic processors (DAIGGER GE 505, $500 \mathrm{~W}, 20 \mathrm{kHz}$ ) immersed directly into the reaction solution. The operating condition was at $30 \mathrm{sec}$ pulse on and $30 \mathrm{sec}$ pulse off time with amplitude of $72 \%$ at $25^{\circ} \mathrm{C}$ for 20 minutes. The mixture was prepared and observed at different $\mathrm{pH}$ (5.5-11) under sonication. $\mathrm{pH}$ measurements of silver nitrate solution were done by using $\mathrm{pH}$ meter (Seven Easy pH, METTLER TOLEDO AG, 8603, Switzerland). The reduction of silver ions was monitored at intervals of hours and days, followed by measurement of the UV-Vis spectra using spectrophotometer (Thermo Spectronic, GENESYS 8, England, Quartz Cell, path length $10 \mathrm{~mm}$ and Graph Plotted on Origin 6.1 program). To find the highest peak or $\lambda_{\max }$, a spectral analysis was carried out by measuring the optical density of the content from wavelength 200 to $800 \mathrm{~nm}$. The particle size distributions of nanoparticles were determined

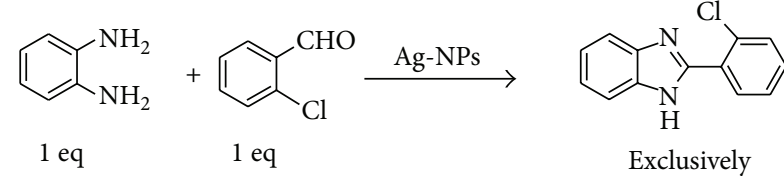

FIGURE 1: Schematic scheme for synthesis of 2-(2-chlorophenyl)-1Hbenzimidazole.

using the HORIBA, Dynamic Light Scattering Version LB550 program. Size and diffraction pattern of nanoparticles are studied on transmission electron microscopy, TEM (FEI, TECNAI, G ${ }^{2}$ spirit twin, Holland). A thin film of the sample was prepared on a carbon-coated copper grid by dropping a very small amount of the sample on the grid. Fourier transform infrared (FTIR-ATR) spectra were recorded on a PerkinElmer (Spectrum two) spectrophotometer to hypothesized functional groups involved in the synthesis of starches Ag-Nps. X-ray diffraction (XRD) studies on thin films of the nanoparticle were carried out using a BRUKER D8 ADVANCE brand $\theta-2 \theta$ configuration (generator-detector) X-ray tube copper $\lambda=1.54 \AA$ and LYNXEYE PSD detector. The diffracted intensities were recorded from $20^{\circ}$ to $70^{\circ} 2 \theta$ angles.

2.3. Synthesis and Characterization of 2-(2-Chlorophenyl)1 H-benzimidazole. A mixture of 1,2-phenylenediamine $(1.0 \mathrm{mmol})$ and $o$-chlorobenzaldehyde $(1.0 \mathrm{mmol})$ in acetonitrile $(3.0 \mathrm{~mL})$ was taken, and $100 \mu \mathrm{L}$ of $\mathrm{Ag}-\mathrm{Nps}$ was added at room temperature. The reaction solution was stirred at room temperature for 10 minutes. The reaction was monitored until its completion by thin layer chromatography (TLC). The filtrate was evaporated under vacuum and subsequently dried to afford the crude product which was purified by column chromatography using hexane/ethyl acetate as eluent to afford pure benzimidazole (approx. 95\%). The structure was characterized by NMR, ESI-MS, and melting point. ${ }^{1} \mathrm{HNMR}$ spectra of $\mathrm{CDCl}_{3}$ solutions were obtained with an Advance 500 (Model: Bruker, 11.4 Tesla, $500 \mathrm{MHz}$ ) spectrometer using tetramethylsilane (TMS) as the internal standard. ESI-MS were obtained on a Varian 91500 LC ion trap mass spectrometer. Melting points determined on a digital Stuart SMP 10 melting point apparatus (ST15, OSA, UK) are uncorrected. The thin layer chromatography (TLC) was performed using the aluminum sheets coated with silica gel 60 (MERCK) containing fluorescent indicators, F254.

\section{Results and Discussion}

3.1. Comparative Study of Carboxymethyl Cellulose, Starch, and Sucrose under Sonication at $p H$ 8.5. The bonding nature of carbohydrate plays an important role in reduction of silver ion into Ag-Nps. So, it is very important deciding factor for choosing bioreductant. We started our experiments as hit and trial method with carboxymethyl cellulose (CMC), starch, and sucrose at $\mathrm{pH} 8.5$ under sonication. Addition of $25 \mathrm{mg}$ of CMC (90,000 MW), starch, and sucrose to the $1 \mathrm{mM}$ AgNO3 solution, the reaction completed by $20 \mathrm{~min}$ with 


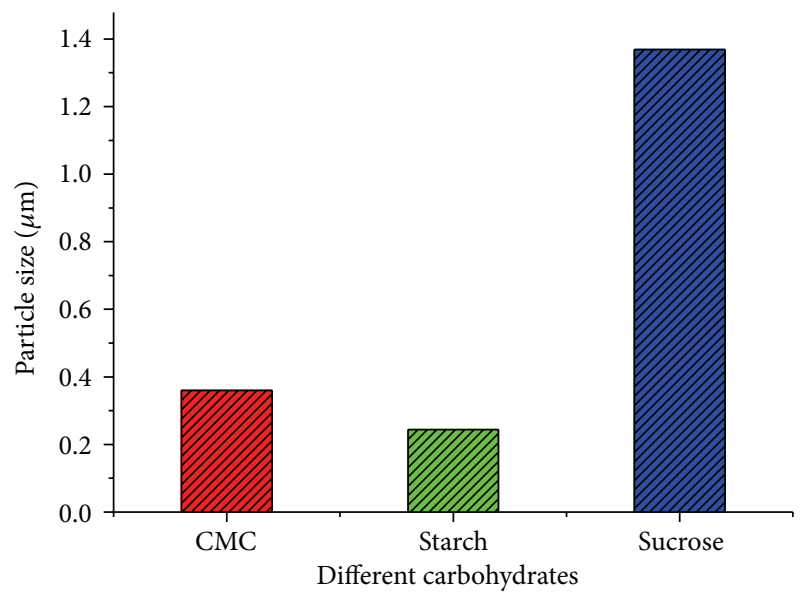

FIGURE 2: Size of Ag-Nps synthesized by using different carbohydrates at $\mathrm{pH} 8.5$.

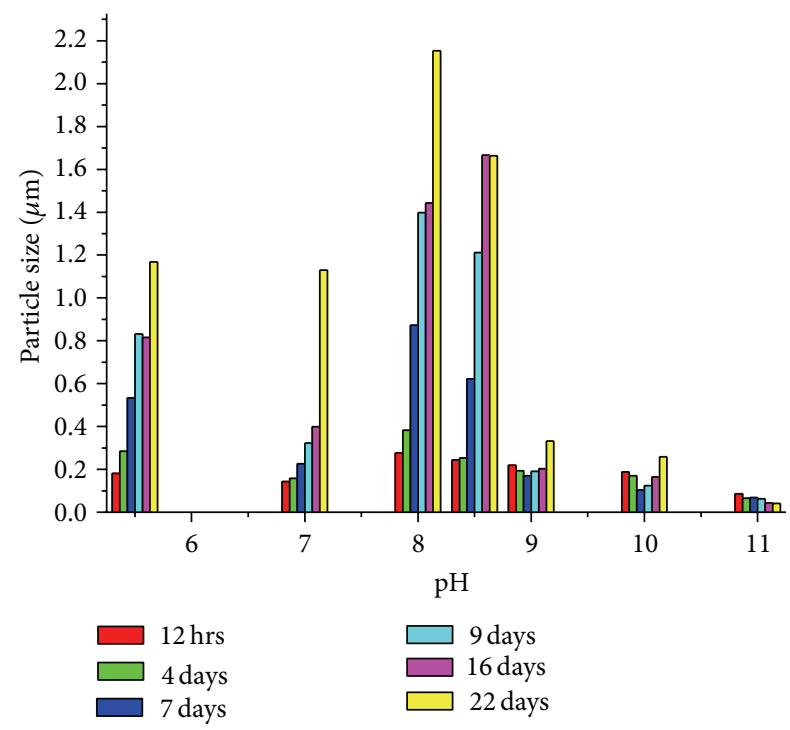

Figure 3: Effect of $\mathrm{pH}$ on particle size at different time duration.

change of light yellow color. Particle size analyzer (DLS) used to examine the size of controlled nanoparticles in aqueous suspensions. Figure 2 shows the comparative graph of size of Ag-Nps which was recorded after the completion of the reaction. We observed that starch $(0.2437 \mu \mathrm{m})$ has given better result in comparison to CMC $(0.3595 \mu \mathrm{m})$ and sucrose $(1.369 \mu \mathrm{m})$. The cause behind this observation was that starch is polysaccharide that has $\alpha$-glycosidic bond (which is a covalent bond between two monosaccharides that involves the carbon $\mathrm{Cl}$ anomeric of the first unit of glucose and carbon C4 of the second unit of glucose) which cleaved under basic medium and sonication to give free aldehyde group. So, it acts as reducing sugar and reduces $\mathrm{Ag}+$ to $\mathrm{Ag}$-Nps and gluconic acid [10] whereas CMC has also o-glycosidic but less tendency to reduce due to its high cross-linking structure [31]. Sucrose is a disaccharide consisting of one unit of $\alpha$-glucose and one unit of $\beta$-fructose linked by $\beta$ glycosidic bonds, which is a covalent bond between two monosaccharides that involves carbon $\mathrm{Cl}$ (anomeric) of the

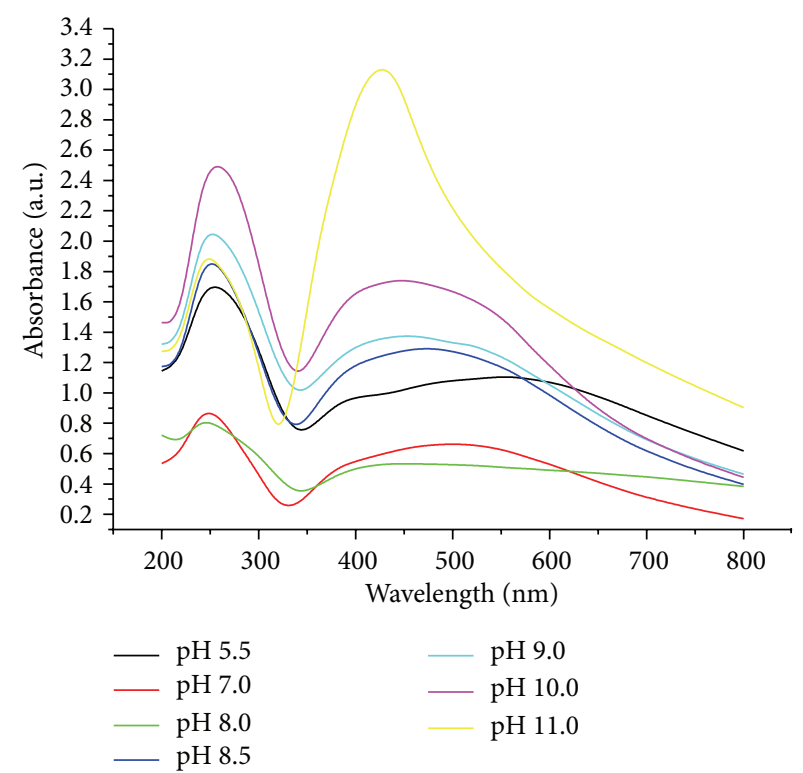

FIGURE 4: UV-Vis spectra at different $\mathrm{pH}$ after 4 days.

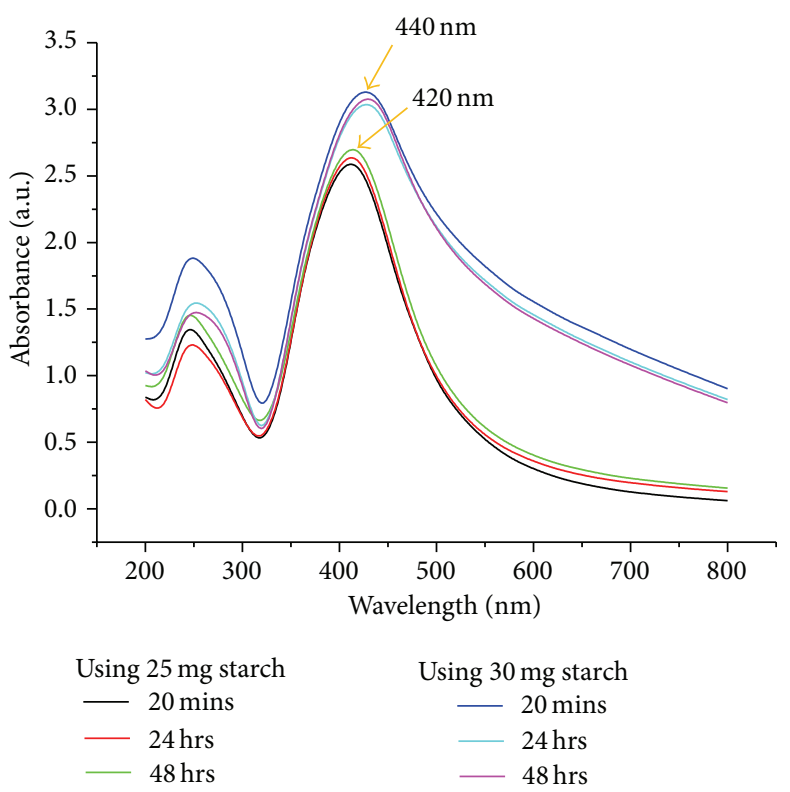

Figure 5: UV-Vis spectra of Ag-Nps at different time at $\mathrm{pH} 11$.

glucose and carbon $\mathrm{C} 2$ of the fructose. So it has less tendency due to its nonreducing $\beta$-glycosidic bond [20]. On looking this reducing and stabilizing nature of starch, we started our further experiment only with starch.

3.2. Effect of $\mathrm{pH}$ on Particle Size. The $\mathrm{pH}$ of $10 \mathrm{~mL}, 1 \mathrm{mM}$ silver nitrate was adjusted to $5.5,7,8,8.5,9,10$, and 11 using dilute sodium hydroxide $(0.1 \mathrm{~N}) ; 25 \mathrm{mg}$ starch was added with continuous stirring. After complete addition, the reaction was allowed to proceed under sonication for 20 mins whereby silver colloid was formed (Table 1). It is important to note that we performed the reaction up to $\mathrm{pH} 11$ because the 
TABLE 1: Average size of sonochemical starched Ag-NPs at different pH.

\begin{tabular}{lcccc}
\hline $\mathrm{AgNO}_{3} /$ starch $(1 \mathrm{mM})$ & $\mathrm{pH}$ & Sonication time & UV-visible absorption $(\mathrm{nm})$ & Average particle size $(\mu \mathrm{m})$ \\
\hline $10 \mathrm{~mL} / 25 \mathrm{mg}$ & 5.5 & $20 \mathrm{~min}$ & 560 & 0.1811 \\
$10 \mathrm{~mL} / 25 \mathrm{mg}$ & 7.0 & $20 \mathrm{~min}$ & 500 & 0.1424 \\
$10 \mathrm{~mL} / 25 \mathrm{mg}$ & 8.0 & $20 \mathrm{~min}$ & 440 & 0.2757 \\
$10 \mathrm{~mL} / 25 \mathrm{mg}$ & 8.5 & $20 \mathrm{~min}$ & 480 & 0.2558 \\
$10 \mathrm{~mL} / 25 \mathrm{mg}$ & 9.0 & $20 \mathrm{~min}$ & 460 & 0.2192 \\
$10 \mathrm{~mL} / 25 \mathrm{mg}$ & 10.0 & $20 \mathrm{~min}$ & 440 & 0.1876 \\
$10 \mathrm{~mL} / 25 \mathrm{mg}$ & 11.0 & $20 \mathrm{~min}$ & 420 & 0.0857 \\
$10 \mathrm{~mL} / 30 \mathrm{mg}$ & 11.0 & $20 \mathrm{~min}$ & 440 & 0.0978 \\
\hline
\end{tabular}

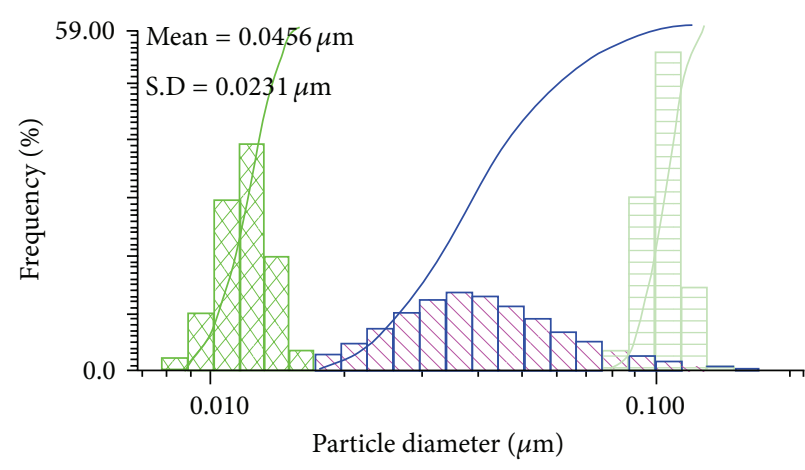

(a)

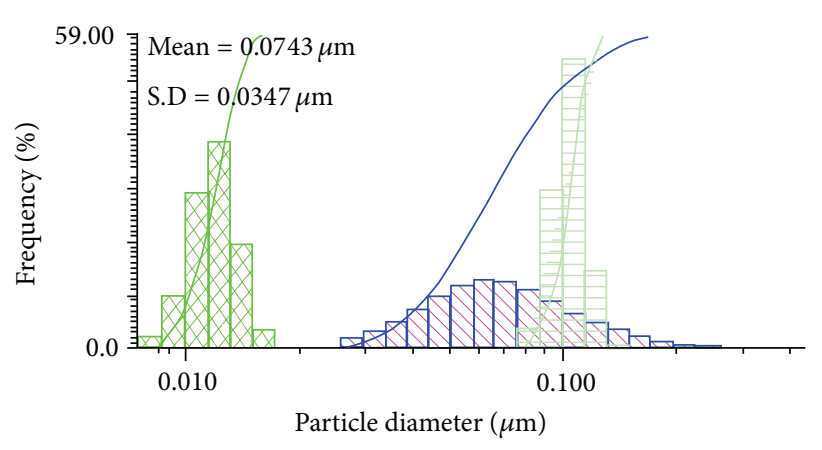

(b)

FIGURE 6: DLS image of Ag-NPs synthesized under ultrasonic irradiation for $20 \mathrm{~min}$, after 4 days: (a) $25 \mathrm{mg}$ and (b) $30 \mathrm{mg}$ starch.

very high alkaline condition of the medium may lead to weakening of the association (H-bonding) even for the starch matrix and thereby diminishing its templating potential to support small sized nanoparticles [32]. A further increase in the basicity of the medium may be resulting in a red shift of the peak position. Figure 3 shows the respective graph of particle size (DLS) of the silver colloid obtained using starch as reducing and stabilizing agent at different $\mathrm{pHs}$. The results reveal a number of observations which may be summarized as follows: (a) increasing the $\mathrm{pH}$ of the solution from 5.5 to 8.0 is accompanied by increase of particle size and $\mathrm{pH}$ of the solution from 8.0 to 11.0 abrupt decrease of particle size; (b) the smallest particle size was observed at $\mathrm{pH} 11$ and the size of Ag-Nps decreases with time from 4 hrs to 22 days $(0.0857$ to $0.0411 \mu \mathrm{m}$ ); (c) particle size continuously increases with time from $\mathrm{pH} 5.5$ to 8.5 in the reaction mixture; $(\mathrm{d})$ the particle size decreases from $12 \mathrm{hrs}$ to 9 days and then increases from 9 days to 22 days at $\mathrm{pH} 9$ and 10; (e) when the $\mathrm{pH} 11$ is targeted, the size becomes smaller and could be assigned to the Ag-Nps.

3.3. Effect of $p H$ on $U V$-Visible Absorbance. Figure 4 shows the UV-Vis spectra of the silver colloid obtained using starch as reducing and stabilizing agent at different pHs. In acidic $\mathrm{pH}$, the association between the functional groups of starch through $\mathrm{H}$-bonding is expected to be more pronounced, which stabilizes the structures and as a result of which these compounds are not effectively utilized in the reduction process. This feature is reversed with the increase in basicity. With the increase of $\mathrm{pH}$ up to 11 , the intensity of the peak at $420 \mathrm{~nm}$ kept on increasing which indicates the progressive generation of the nanoparticles. The results reveal a number of observations which may be summarized as follows: (a) increasing the $\mathrm{pH}$ of the solution is accompanied by appreciable changes in the electronic absorption spectra; (b) a band at higher energy, that is, $240 \mathrm{~nm}$, appears at $\mathrm{pH} 10$ and the intensity of this band decreases by decreasing the $\mathrm{pH}$ up to 5.5; (c) further decreases in the $\mathrm{pH}$ of the reaction medium up to $\mathrm{pH} 11$ lead to lowering intensity of this band; (d) simultaneously, another band at $420 \mathrm{~nm}$ starts to appear and the absorption peak that appeared is attributed to the surface plasmon excitation of silver particles and reaches its maximum intensity at $\mathrm{pH} 11$; (e) when the range of $\mathrm{pH} 11$ is targeted, the band becomes stronger and could be assigned to the plasmon resonance of Ag-Nps.

\subsection{Effect of Starch on Particle Size}

3.4.1. UV-Visible and DLS Analysis of Ag-Nps. Figure 5 shows the UV-Vis absorption spectra of silver nanoparticles colloidal solutions prepared at different amounts of starch (25 and $30 \mathrm{mg}$ ) at $\mathrm{pH} 11$. The data reveal several important findings which can be presented as follows: (i) using 25 and $30 \mathrm{mg}$ of starch with $1 \mathrm{mM} \mathrm{AgNO}_{3}$ reaction under $20 \mathrm{~min}$ sonication leads to outstanding enhancement in the plasmon intensity indicating that large amounts of silver ions are reduced and used for cluster formation; (ii) keeping both reactions ( 25 and $30 \mathrm{mg}$ starch) from $20 \mathrm{~min}$ to $48 \mathrm{hrs}$ is accompanied by marginal increment in the absorption intensity which could be attributed to stability of Ag-Nps; (iii) the absorption intensity observed at $420 \mathrm{~nm}$ and $440 \mathrm{~nm}$ reveals 


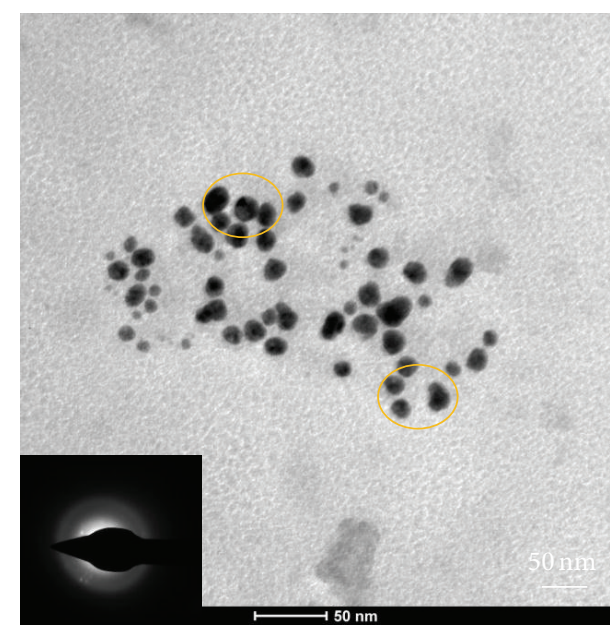

(a)

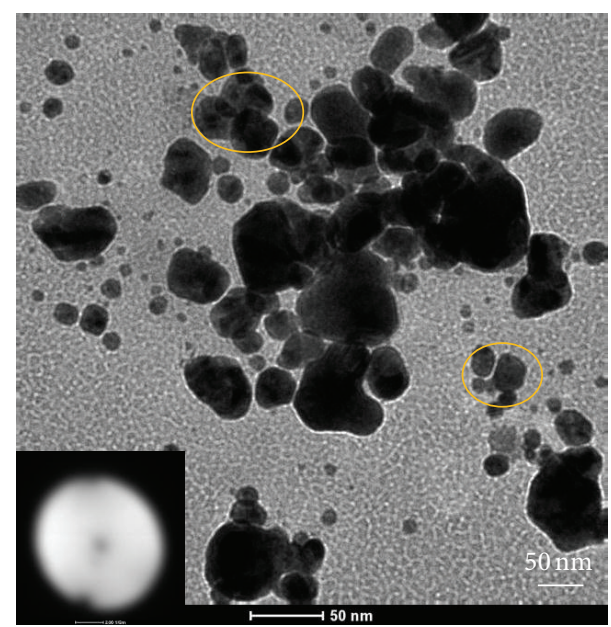

(b)

FIgURE 7: TEM and SAED pictures of Ag-Nps: (a) $25 \mathrm{mg}$ starch and (b) $30 \mathrm{mg}$ starch.

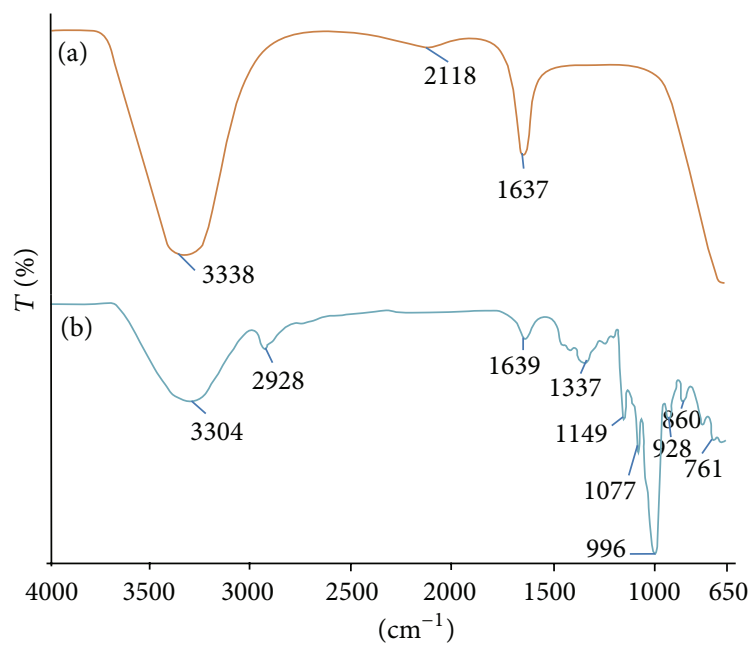

Figure 8: FT-IR spectrum (a) synthesized Ag-Nps (b) Starch.

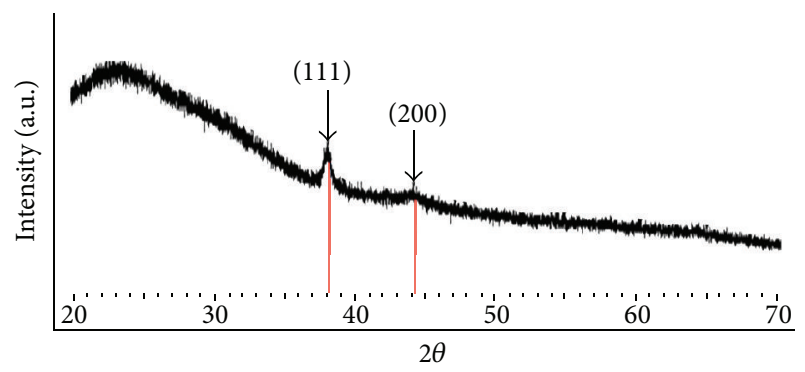

FIGURE 9: X-ray diffraction pattern of starch impregnated with AgNPs.

some aggregation of Ag-Nps at $30 \mathrm{mg}$ starch; (iv) increasing the reaction duration up to $48 \mathrm{hrs}$, the band becomes stronger and could be assigned to the plasmon resonance of Ag-Nps at 420 and $440 \mathrm{~nm}$. Figure 6 shows the size distribution of 25 and $30 \mathrm{mg}$ starched Ag-Nps; mean and standard deviation for $25 \mathrm{mg}$ starched Ag-Nps was 0.0456 and $0.0231 \mu \mathrm{m}$ whereas for
$30 \mathrm{mg}$ starched Ag-Nps was 0.0743 and $0.0231 \mu \mathrm{m}$. DLS study reveals that the size of $25 \mathrm{mg}$ starched Ag-Nps is smaller than $30 \mathrm{mg}$; its value also agrees with the interpretation UV-Vis data (220 and $240 \mathrm{~nm}$ ) due to aggregation of starched Ag-Nps at higher concentration.

3.4.2. TEM and SAED Analyses of Ag-Nps. Figure 7 shows the TEM images of Ag-Nps formed after 4 days. TEM image shows small spherical shape and polydispersed particles. The corresponding average size distribution for $25 \mathrm{mg}$ starched Ag-Nps is 10 to $25 \mathrm{~nm}$ whereas $30 \mathrm{mg}$ starched Ag-Nps are 23 to $97 \mathrm{~nm}$. The Ag-Nps are spherical in shape, selected area electron diffraction pattern explains their partial crystalline nature, and are not aggregated in solution with $25 \mathrm{mg}$ starch for 20 min sonication (Figure 7(a)). This is due to the binding force between the Ag-NPs and the capping molecules that may get decreased whereas $30 \mathrm{mg}$ starched Ag-Nps were aggregated. The diffuse band in the electron diffraction pattern is due to the presence of starch and explains amorphous nature Ag-Nps (Figure 7(b)). The smallest size of the synthesized $\mathrm{Ag}-\mathrm{Nps}$ is $10 \mathrm{~nm}$ and $23 \mathrm{~nm}$ by using 25 and $30 \mathrm{mg}$ starch, respectively.

3.4.3. FTIR Analysis of Ag-Nps. FT-IR measurements were carried out to identify the possible functional group responsible for the reduction of the $\mathrm{Ag}^{+}$ions and capping of the bioreduced Ag-Nps synthesized by starch. Figure 8(b) represents the FTIR spectrum of starch and shows bands at $3304 \mathrm{~cm}^{-1}$ for $-\mathrm{OH}$ stretching (aliphatic hydroxyl group), $2928 \mathrm{~cm}^{-1}$ for $\mathrm{C}-\mathrm{H}$ stretching (aliphatic C-H), and $1639 \mathrm{~cm}^{-1}$ for carbonyl stretching ( $\mathrm{C}=\mathrm{O}$, carbonyl group). In Figure 8(a), there is deviation of both hydroxyl and carbonyl group; it appears at 3338 and $1637 \mathrm{~cm}^{-1}$, indicating that both were involved in synthesis of Ag-Nps.

3.4.4. XRD Analysis of Ag-Nps. In the XRD spectrum (Figure 9), the broad reflexion at $20^{\circ}$ to $30^{\circ}$ is due to the low 


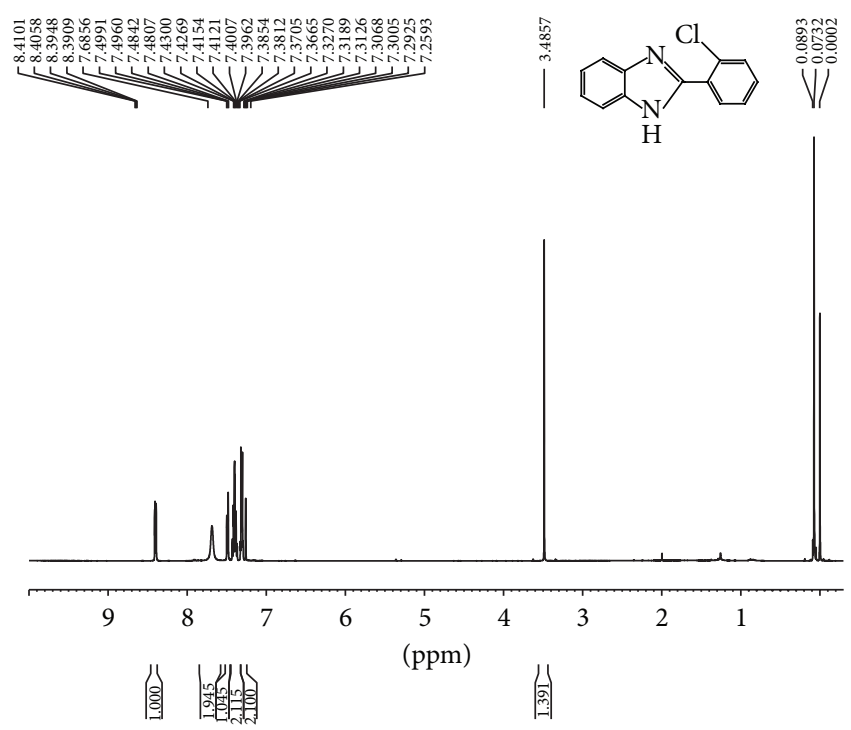

(a)

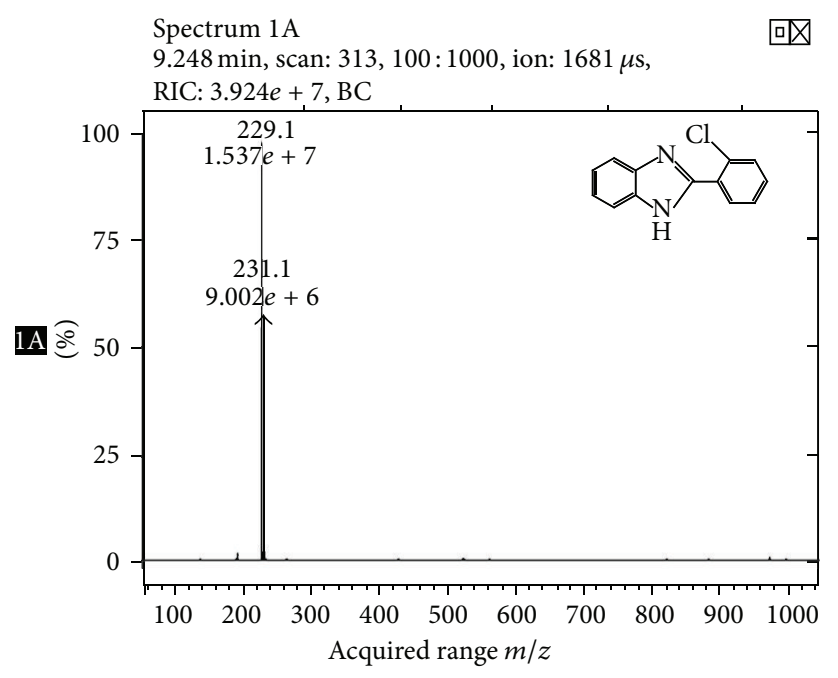

(b)

FIGURE 10: (a) ${ }^{1}$ H NMR and (b) ESI-MS spectra of 2-(2-chlorophenyl)-1H-benzimidazole.

crystallinity of the starch, and other peaks are assigned to diffractions from the (111) and (200) planes of face-centred cubic (fcc) silver (Ref. no-01-087-0717). SAED pattern of AgNPs (Figure 7) also showed a diffuse band corresponding to the polymorph of starch. Because the diffraction pattern of silver nanoparticles could not be observed, it indirectly explains the amorphous nature of AgNPs. We hypothesized that an extensive number of hydroxyl groups can facilitate the complexation of metal ions to the molecular starch matrix. $\mathrm{Ag}^{+}$reduced to $\mathrm{Ag}$ and $\mathrm{Ag}$ may be completely wrapped or be inside the starch molecule. XRD and SAED pattern indicates the partial amorphous nature of starched AgNPs.

3.4.5. NMR-ESI MS Analysis of 2-(2-Chlorophenyl)-1Hbenzimidazole [33]. We used starched Ag-Nps as catalyst for synthesis of 2-aryl benzimidazole derivatives. In our initial experiments, we choose 1,2-phenylenediamine $(1.0 \mathrm{mmol})$ and $o$-chlorobenzaldehyde $(1.0 \mathrm{mmol})$ as a model reaction for optimization of catalyst and reaction conditions. Figures 10(a) and 10(b) show ${ }^{1}$ HNMR and ESI-MS spectra of 2-(2chlorophenyl)- $1 H$-benzimidazole. These results confirmed that Ag-Nps significantly increased the selectivity for synthesis 2-aryl benzimidazole.

Chemical formula: $\mathrm{C}_{13} \mathrm{H}_{9} \mathrm{ClN}_{2}$; white solid ( 95\%); mp $230-232^{\circ} \mathrm{C} ;{ }^{1} \mathrm{H}$ NMR $\left(500 \mathrm{MHz}, \mathrm{CDCl}_{3}\right): \delta 8.40(\mathrm{dd}, 1 \mathrm{H}), 7.68$ (br, $2 \mathrm{H}), 7.48(\mathrm{~m}, 1 \mathrm{H}), 7.40(\mathrm{~m}, 2 \mathrm{H})$, and $7.31(\mathrm{~m}, 2 \mathrm{H})$; ESI-MS: $m / z=229.1(\mathrm{M}+1)$.

3.4.6. Mechanism for Ag-NP Catalyzed Synthesis of 2-Aryl Benzimidazole. We inspired from oxidative properties of Ag-NPs well documented by Cong et al. for the DielsAlder cycloadditions of $2^{\prime}$-hydroxychalcones [34]. Based on our experimental results we propose the brief working mechanism generated by the AgNP's for the synthesis of 2aryl benzimidazole derivatives as shown in Figure 11. The

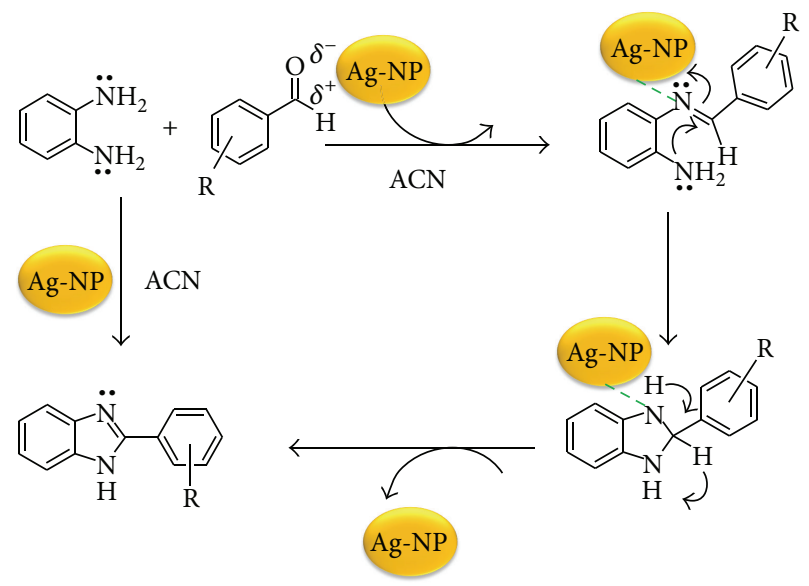

FIGURE 11: Generalized mechanism for Ag-NP catalyzed synthesis of 2-aryl benzimidazole.

existence of electron transfer processes between the AgNP and an aldehyde substrate, consistent with the electron transfer processes in metal nanoparticle-catalyzed oxidation reactions [35-38].

\section{Conclusions}

In summary, we have demonstrated a simple, clean, effective, economical, nontoxic, and environment friendly technique for the synthesis of colloidal silver nanoparticle by using starch as reducing and stabilizing agent under sonication. Sonochemical reduction route demonstrates a remarkable potential for fabricating desired particle size colloidal silver nanoparticles. Absorption spectra confirm the presence of surface plasmon resonance at 420 and $440 \mathrm{~nm}$, characteristic of Ag-Nps. A diverse range of $\mathrm{pH}$ was used to standardize the 
reaction at room temperature. In addition, the use of sonication for synthesis of Ag-Nps is more environmentally friendly and safer than other synthetic methodology. Starched AgNPs showed efficient catalytic activity for the synthesis of 2aryl benzimidazole.

\section{Conflict of Interests}

The authors declare that there is no conflict of interests regarding the publication of this paper.

\section{Acknowledgments}

This scientific work has been funded by the Prometeo Project of the National Secretariat of Science, Technology and Innovation (SENESCYT), Ecuador. The authors thank Dr. Colon Velasquez (Director, INIGEMM, Ecuador) for providing XRD instrumental assistance. they also thank PROINSTRA, Ecuador, for providing FTIR facility.

\section{References}

[1] L. J. Guo, X. Cheng, and C. F. Chou, "Fabrication of sizecontrollable nanofluidic channels by nanoimprinting and its application for DNA stretching," Nano Letters, vol. 4, no. 1, pp. 69-73, 2004.

[2] Q. Xu, B. D. Gates, and G. M. Whitesides, "Fabrication of metal structures with nanometer-scale lateral dimensions by sectioning using a microtome," Journal of the American Chemical Society, vol. 126, no. 5, pp. 1332-1333, 2004.

[3] F. Rosei, "Nanostructured surfaces: challenges and frontiers in nanotechnology," Journal of Physics Condensed Matter, vol. 16, no. 17, pp. S1373-S1436, 2004.

[4] D. Bhattacharya and R. K. Gupta, "Nanotechnology and potential of microorganisms," Critical Reviews in Biotechnology, vol. 25, no. 4, pp. 199-204, 2005.

[5] M. C. Daniel and D. Astruc, "Gold nanoparticles: assembly, supramolecular chemistry, quantum-size-related properties, and applications toward biology, catalysis, and nanotechnology," Chemical Reviews, vol. 104, no. 1, pp. 293-346, 2004.

[6] R. Zamiri, B. Z. Azmi, M. Darroudi et al., "Preparation of starch stabilized silver nanoparticles with spatial self-phase modulation properties by laser ablation technique," Applied Physics A, vol. 102, no. 1, pp. 189-194, 2011.

[7] M. Darroudi, M. B. Ahmad, R. Zamiri et al., "Preparation and characterization of gelatin mediated silver nanoparticles by laser ablation," Journal of Alloys and Compounds, vol. 509, no. 4, pp. 1301-1304, 2011.

[8] N. M. Huang, H. N. Lim, S. Radiman et al., "Sucrose ester micellar-mediated synthesis of Ag nanoparticles and the antibacterial properties," Colloids and Surfaces A, vol. 353, no. 1, pp. 69-76, 2010.

[9] M. Darroudi, M. B. Ahmad, A. H. Abdullah, N. A. Ibrahim, and K. Shameli, "Effect of accelerator in green synthesis of silver nanoparticles," International Journal of Molecular Sciences, vol. 11, no. 10, pp. 3898-3905, 2010.

[10] M. Singh, I. Sinha, and R. K. Mandal, "Role of $\mathrm{pH}$ in the green synthesis of silver nanoparticles," Materials Letters, vol. 63, no. 3-4, pp. 425-427, 2009.
[11] A. Gedanken, "Sonochemistry and its application to nanochemistry," Current Science, vol. 85, no. 12, pp. 1720-1722, 2003.

[12] L. P. Jiang, S. Xu, J. M. Zhu, J. R. Zhang, J. J. Zhu, and H. Y. Chen, "Ultrasonic-assisted synthesis of monodisperse singlecrystalline silver nanoplates and gold nanorings," Inorganic Chemistry, vol. 43, no. 19, pp. 5877-5883, 2004.

[13] J. Zhu, S. Liu, O. Palchik, Y. Koltypin, and A. Gedanken, "Shape-controlled synthesis of silver nanoparticles by pulse sonoelectrochemical methods," Langmuir, vol. 16, no. 16, pp. 6396-6399, 2000.

[14] R. Konwarh, N. Karak, C. E. Sawian, S. Baruah, and M. Mandal, "Effect of sonication and aging on the templating attribute of starch for "green" silver nanoparticles and their interactions at bio-interface," Carbohydrate Polymers, vol. 83, no. 3, pp. 12451252, 2011.

[15] Y. Nagata, Y. Watananabe, S. I. Fujita, T. Dohmaru, and S. Taniguchi, "Formation of colloidal silver in water by ultrasonic irradiation," Journal of the Chemical Society, Chemical Communications, no. 21, pp. 1620-1622, 1992.

[16] R. A. Salkar, P. Jeevanandam, S. T. Aruna, Y. Koltypin, and A. Gedanken, "The sonochemical preparation of amorphous silver nanoparticles," Journal of Materials Chemistry, vol. 9, no. 6, pp. 1333-1335, 1999.

[17] S. Liu, W. Huang, S. Chen, S. Avivi, and A. Gedanken, "Synthesis of X-ray amorphous silver nanoparticles by the pulse sonoelectrochemical method," Journal of Non-Crystalline Solids, vol. 283, no. 1-3, pp. 231-236, 2001.

[18] I. A. Wani, A. Ganguly, J. Ahmed, and T. Ahmad, "Silver nanoparticles: ultrasonic wave assisted synthesis, optical characterization and surface area studies," Materials Letters, vol. 65, no. 3, pp. 520-522, 2011.

[19] H. S. Shin, H. J. Yang, S. B. Kim, and M. S. Lee, "Mechanism of growth of colloidal silver nanoparticles stabilized by polyvinyl pyrrolidone in $\gamma$-irradiated silver nitrate solution," Journal of Colloid and Interface Science, vol. 274, no. 1, pp. 89-94, 2004.

[20] E. Filippo, A. Serra, A. Buccolieri, and D. Manno, "Green synthesis of silver nanoparticles with sucrose and maltose: morphological and structural characterization," Journal of NonCrystalline Solids, vol. 356, no. 6-8, pp. 344-350, 2010.

[21] Y. K. Twu, Y. W. Chen, and C. M. Shih, "Preparation of silver nanoparticles using chitosan suspensions," Powder Technology, vol. 185, no. 3, pp. 251-257, 2008.

[22] I. Medina-Ramirez, S. Bashir, Z. Luo, and J. L. Liu, "Green synthesis and characterization of polymer-stabilized silver nanoparticles," Colloids and Surfaces B, vol. 73, no. 2, pp. 185191, 2009.

[23] H. Bar, D. K. Bhui, G. P. Sahoo, P. Sarkar, S. P. De, and A. Misra, "Green synthesis of silver nanoparticles using latex of Jatropha curcas," Colloids and Surfaces A, vol. 339, no. 1-3, pp. 134-139, 2009.

[24] D. Philip, C. Unni, S. A. Aromal, and V. K. Vidhu, "Murraya Koenigii leaf-assisted rapid green synthesis of silver and gold nanoparticles," Spectrochimica Acta A, vol. 78, no. 2, pp. 899904, 2011.

[25] D. Philip, "Mangifera Indica leaf-assisted biosynthesis of welldispersed silver nanoparticles," Spectrochimica Acta A, vol. 78, no. 1, pp. 327-331, 2011.

[26] E. J. Guidelli, A. P. Ramos, M. E. D. Zaniquelli, and O. Baffa, "Green synthesis of colloidal silver nanoparticles using natural rubber latex extracted from Hevea brasiliensis," Spectrochimica Acta A, vol. 82, no. 1, pp. 140-145, 2011. 
[27] D. K. Bozanic, V. Djokovic, J. Blanusa, P. S. Nair, M. K. Georges, and T. Radhakrishnan, "Preparation and properties of nanosized Ag and Ag2S particles in biopolymer matrix," European Physical Journal E, vol. 22, pp. 51-59, 2007.

[28] Z. Shervani, Y. Ikushima, M. Sato et al., "Morphology and size-controlled synthesis of silver nanoparticles in aqueous surfactant polymer solutions," Colloid and Polymer Science, vol. 286, no. 4, pp. 403-410, 2008.

[29] N. Vigneshwaran, R. P. Nachane, R. H. Balasubramanya, and P. V. Varadarajan, "A novel one-pot 'green' synthesis of stable silver nanoparticles using soluble starch," Carbohydrate Research, vol. 341, no. 12, pp. 2012-2018, 2006.

[30] V. K. Sharma, R. A. Yngard, and Y. Lin, "Silver nanoparticles: green synthesis and their antimicrobial activities," Advances in Colloid and Interface Science, vol. 145, no. 1-2, pp. 83-96, 2009.

[31] A. A. Hebeish, M. H. El-Rafie, F. A. Abdel-Mohdy, E. S. AbdelHalim, and H. E. Emam, "Carboxymethyl cellulose for green synthesis and stabilization of silver nanoparticles," Carbohydrate Polymers, vol. 82, no. 3, pp. 933-941, 2010.

[32] R. Konwarh, N. Karak, C. E. Sawian, S. Baruah, and M. Mandal, "Effect of sonication and aging on the templating attribute of starch for "green" silver nanoparticles and their interactions at bio-interface," Carbohydrate Polymers, vol. 83, no. 3, pp. 12451252, 2011.

[33] M. A. Chari, D. Shobha, E. R. Kenawy, S. S. Al-Deyab, B. V. S. Reddy, and A. Vinu, "Nanoporous aluminosilicate catalyst with $3 \mathrm{D}$ cage-type porous structure as an efficient catalyst for the synthesis of benzimidazole derivatives," Tetrahedron Letters, vol. 51, no. 39, pp. 5195-5199, 2010.

[34] H. Cong, C. F. Becker, S. J. Elliott, M. W. Grinstaff, and J. A. Porco Jr., "Silver nanoparticle-Catalyzed diels-alder cycloadditions of 2' -hydroxychalcones," Journal of the American Chemical Society, vol. 132, no. 21, pp. 7514-7518, 2010.

[35] A. Grirrane, A. Corma, and H. García, "Gold-catalyzed synthesis of aromatic azo compounds from anilines and nitroaromatics," Science, vol. 322, no. 5908, pp. 1661-1664, 2008.

[36] S. G. Sudrik, N. K. Chaki, V. B. Chavan et al., "Silver nanocluster redox-couple-promoted nonclassical electron transfer: an efficient electrochemical wolff rearrangement of $\alpha$-diazoketones," Chemistry, vol. 12, no. 3, pp. 859-864, 2006.

[37] R. Xu, D. Wang, J. Zhang, and Y. Li, "Shape-dependent catalytic activity of silver nanoparticles for the oxidation of styrene," Chemistry, vol. 1, no. 6, pp. 888-893, 2006.

[38] D. P. Debecker, C. Faure, M. E. Meyre, A. Dené, and E. M. Gaigneaux, "A new bio-inspired route to metal-nanoparticlebased heterogeneous catalysts," Small, vol. 4, no. 10, pp. 18061812, 2008. 

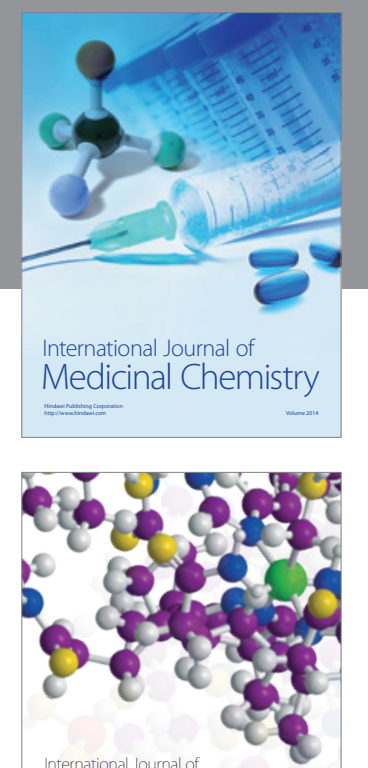

\section{Carbohydrate} Chemistry

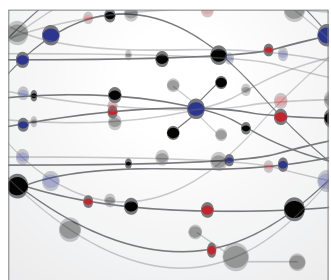

The Scientific World Journal
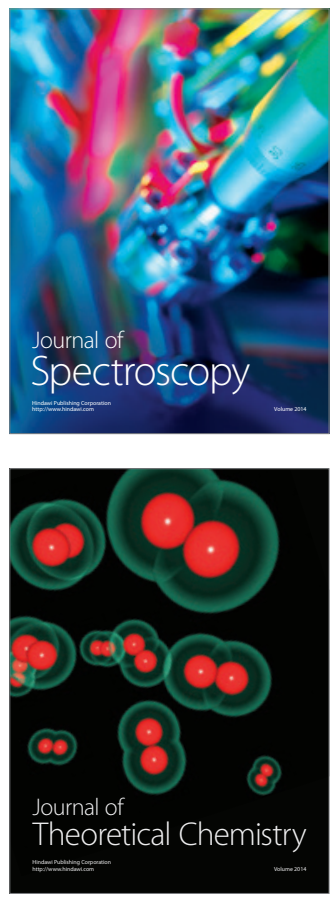
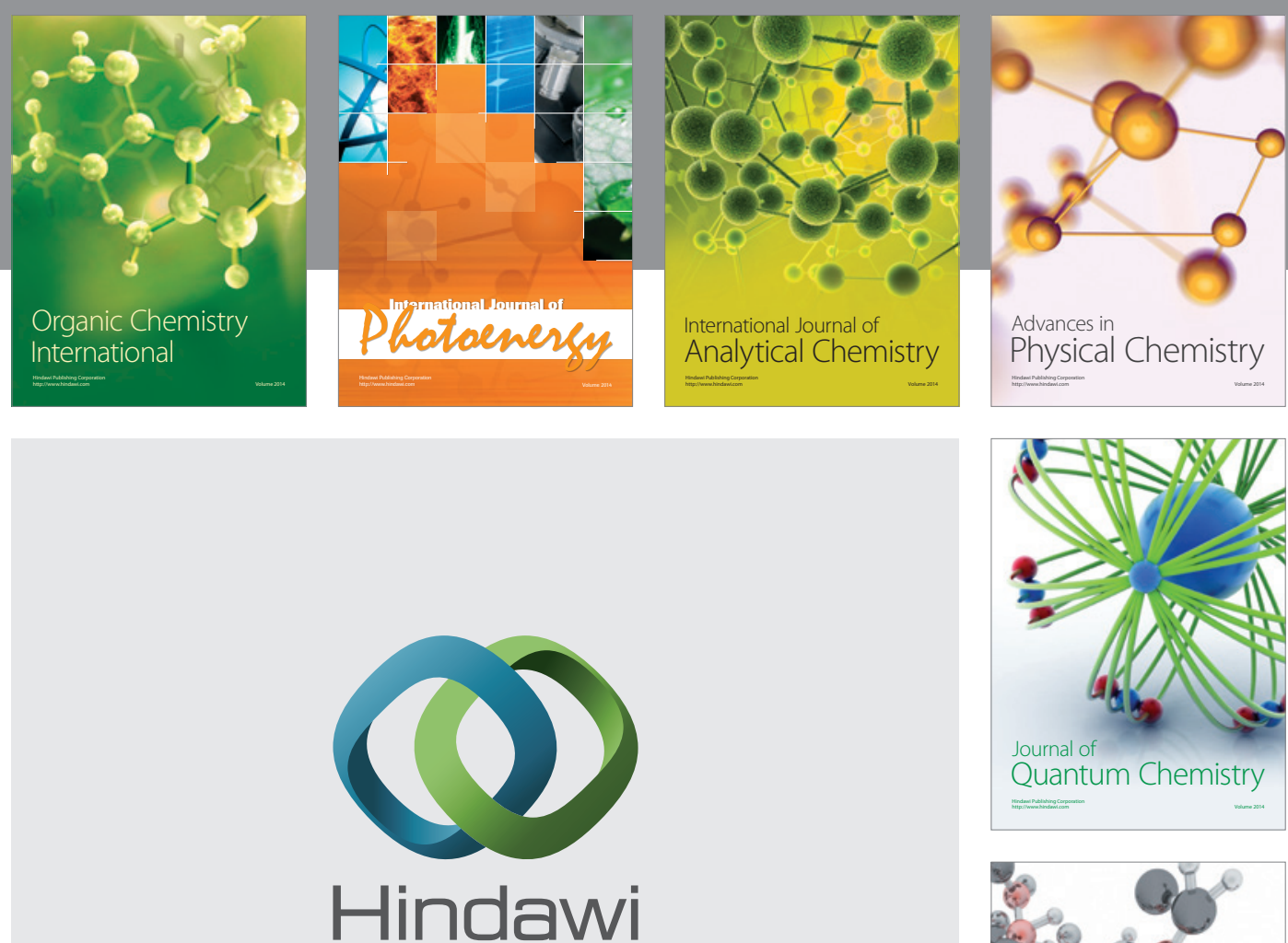

Submit your manuscripts at

http://www.hindawi.com

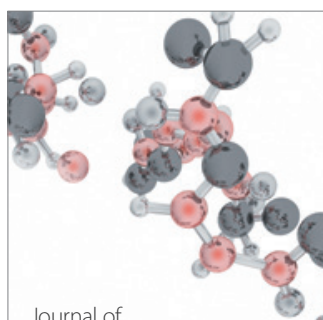

Analytical Methods

in Chemistry

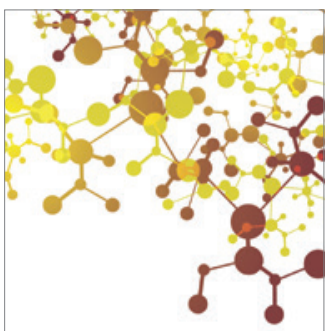

Journal of

Applied Chemistry

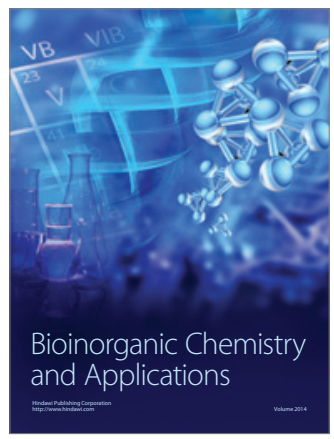

Inorganic Chemistry
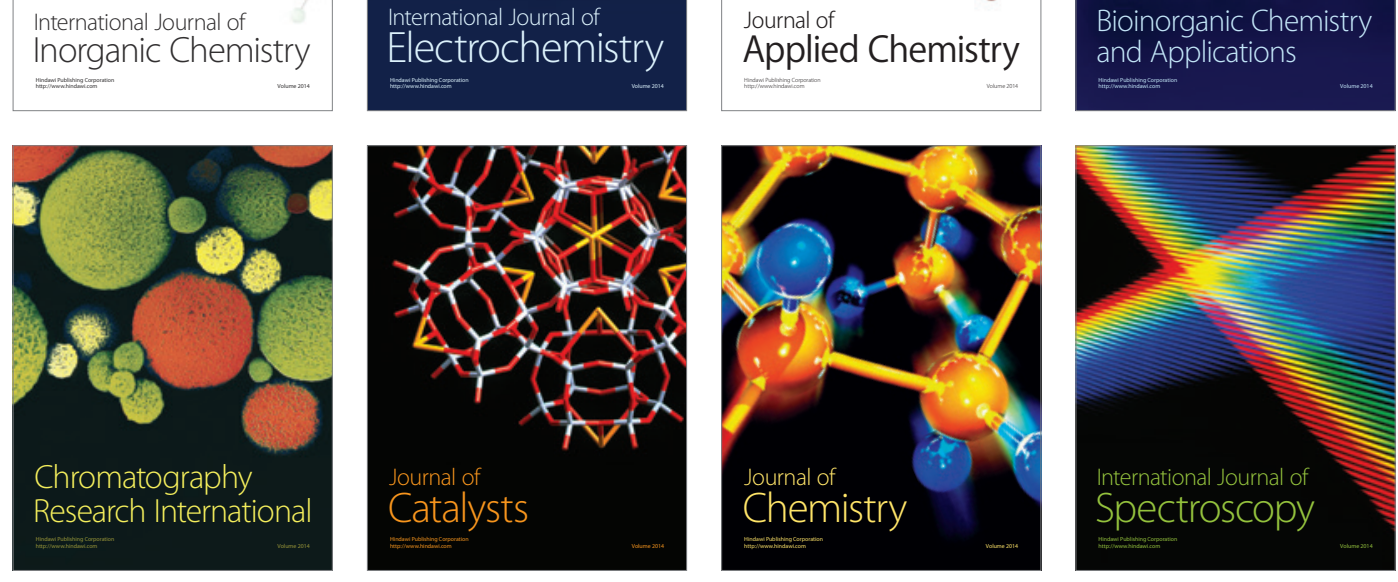